\title{
Integrin dependent migration of lung cancer cells to extracellular matrix components
}

\author{
C.G. Bredin*,**, K-G. Sundqvist**,, D. Hauzenberger**,, J. Klominek****
}

Integrin dependent migration of lung cancer cells to extracellular matrix components. C.G. Bredin, K-G. Sundqvist, D. Hauzenberger, J. Klominek. (OERS Journals Ltd 1998. ABSTRACT: Since tumour progression is dependent on the ability of malignant cells to interact with the extracellular matrix (ECM), we have investigated the significance of $\beta 1$ and $\beta 3$ integrins for migration of lung cancer cells to components of the ECM.

In an in vitro hapto- and chemotactic assay system, five cell lines representing the major types of lung cancer were examined: adenocarcinoma (WART); squamous cell carcinoma (U-1752); small cell lung cancer (SCLC) (U-1906, 054 A) and large cell lung cancer (LCLC) (U-1810). Flow cytometric analyses were performed to characterize their integrin expression.

U-1906, 054 A, WART and U-1752 all expressed $\beta 1$ integrins whereas U-1810 did not. However, U-1810 and U-1752 expressed $\beta 3$ integrins. All cell lines except U-1810 and U-1752 showed hapto- and chemotactic motility to fibronectin, laminin and type IV collagen and this motility was $\beta 1$ integrin-dependent except in the case of U-1810. However, the hapto- and chemotactic responses differed markedly between the separate cell lines and there was no distinct pattern to separate non-small cell lung cancer (NSCLC) from SCLC. No or very little migration was seen in control experiments with bovine serum albumin (BSA) or serum-free medium alone, indicating that the migration of the lung cancer cells require adhesion molecules, soluble or substratum bound.

We have found the involvement of $\beta 1$ integrins in lung cancer cell migration in vitro towards fibronectin, laminin and type IV collagen except in the case of U-1810. The U-1810 cell line clearly differed from the rest of the cell lines by lacking expression of $\beta 1$ integrins.

Eur Respir J 1998; 11: 400-407.
*Dept of Lung Medicine and **Dept of Clinical Immunology, Karolinska Institute at Huddinge University Hospital, Huddinge, Sweden. ${ }^{+}$Dept of Clinical Immunology, Umeå University Hospital, Umeå, Sweden.

Correspondence: J. Klominek

Dept of Lung Medicine

M53

Huddinge University Hospital

S-141 86 Huddinge

Sweden

Fax: 4687117306

Keywords: Extracellular matrix, integrins, invasion, lung cancer, migration

Received: February 181997

Accepted after revision December 191997

This work has been supported by Swedish Cancer Society 3549-B94-1XA (grants to J.K.) and 1940-B90 (grants to K.-G.S.), Swedish Society of Medicine (grants to J.K.), Swedish Medical Research Council 16X-08295 (grants to K-G.S.), Swedish Heart Lung Foundation.
Metastasis is a complex process consisting of abnormalities in regulation of cell growth and cell migration. Understanding of the mechanisms of tumour invasiveness, migration and aggressiveness is a future key to improved treatment of cancer patients. Tumour cells of any histological origin must penetrate the extracellular matrix (ECM) at many stages of tumour invasion and metastasis, e.g. during intra- and extravasation $[1,2]$. The ECM separates different tissue compartments, and type IV collagen is the structural backbone of the particular part of the matrix called the basement membrane. The basement membrane is normally impermeable to large proteins and cells. However, during tumour cell invasion tumour cells attach to components of the ECM and the basement membrane, degrade it and migrate through the matrix [3]. Components of the ECM including fibronectin, laminin and type IV collagen, as well as their proteolytic digestion products, also stimulate the in vitro migration of a variety of normal cells and tumour cells $[2,4,5]$.

Many of the adhesive interactions of cancer cells with the ECM are mediated by the $\beta 1$ integrin family of cell surface receptors. Structurally the integrins are transmembrane glycoproteins that form heterodimers consisting of a single $\beta$ subunit noncovalently linked to one of several possible $\alpha$ subunits. The receptor complex spans the plas- ma membrane, linking the internal cytoskeletal network of a cell to the ECM. The particular combination of $\alpha$ and $\beta$ subunits determines the specificity for ligand binding [6-8].

$\beta 1$ integrins appear to play a central role in migration of different human tumour cell lines including fibrosarcoma, bladder carcinoma and colon carcinoma [9]. The role of integrins for the migration of lung cancer cells has not been extensively investigated. In addition to mediating cell adhesion and motility the $\beta 1$ integrin family also participates in signal transduction processes $[10,11]$, tumourigenicity $[12,13]$ and growth regulation $[6,13]$. The $\beta 3$ class of integrins includes: the platelet glycoprotein IIb/IIIa complex ( $\alpha \mathrm{IIb} \beta 3$ ); and $\alpha \mathrm{v} \beta 3$ which binds fibronectin, fibrinogen, vitronectin, thrombospondin, and von Willebrands factor [8].

Changes in expression or modification of the integrins have been noted during malignant transformation in various cells [14-16]. However, only a few studies have reported a clear correlation between the degree of transformation or malignancy and the pattern of the integrin expression. For example, high levels of expression of the $\alpha 5 \beta 1$ integrin seem to be negatively correlated with transformation and tumour formation in Chinese hamster ovary cell variants $[12,13]$, whereas increased expression of $\alpha \mathrm{v} \beta 3$ seems to be positively correlated with increased metastatic ability 
in melanomas [14]. Increased expression of $\alpha 1 \beta 1$ and $\alpha 2 \beta 1$ has been shown to be positively correlated with increased metastatic ability in human squamous cell lung cancer cells when i.v. inoculated in severe combined immunodeficiency (SCID) mice [17].

The purpose of this study was: 1) to compare haptoand chemotactic migration (migration in response to substratum bound and to soluble attractants respectively) of five established lung cancer lines, representing four major types of lung cancer, to fibronectin, laminin and type IV collagen; 2 ) to determine the $\beta 1$-integrin repertoire of these lung cancer lines; and 3 ) to test if the $\beta 1$ integrins play a role in lung tumour cell motility.

\section{Materials and methods}

\section{Cells and culture conditions}

The cell lines studied: lung adenocarcinoma (WART) [18], squamous cell carcinoma (U-1752) [19], large cell lung cancer (LCLC) (U-1810) and small cell lung cancer (SCLC) (U-1906, 054 A) $[20,21]$ are well characterized and described previously. All cell lines were cultured in RPMI 1640 medium (GIBCO BRL; Life Technologies Ltd, Paisley, UK) supplemented with $10 \%$ foetal calf serum (SS medium), $2 \mathrm{mM}$ L-glutamin, $50 \mathrm{IU} \cdot \mathrm{mL}^{-1}$ penicillin, and $50 \mu \mathrm{g} \cdot \mathrm{mL}^{-1}$ streptomycin (GIBCO), in a humidified atmosphere of $5 \% \mathrm{CO}_{2}$ in air at $37^{\circ} \mathrm{C}$. Human umbilical vein endothelial cells (HUVECs) were generously provided by S. Sumitran-Karuppan (Karolinska Institute at Huddinge University Hospital, Huddinge, Sweden). They were prepared and cultured as previously described [22]. For the experiments all cells were harvested near confluence.

\section{Adhesion proteins}

Fibronectin was purchased from Boerhinger Mannheim (Mannheim, Germany) type IV collagen and laminin were obtained from Sigma (Stockholm, Sweden).

\section{In vitro cell migration assays}

The motility of lung cancer cells was studied using 48 well microchemotaxis chambers (NeuroProbe, Cabin John, MA, USA) fitted with $12 \mu \mathrm{m}$ polyvinylpyrrolidone-free polycarbonate (PVP)-free filters (Poretics, Livermore, CA, USA) as previously described [23]. Briefly the cells were removed with trypsin $(0.25 \%)$ and ethylenediaminetetraacetic acid (EDTA) $(0.02 \%)$ both from Flow Laboratories (Poole, UK). After pre-incubation with serum-containing medium for 30 min and one wash with Dulbecco's phosphate-buffered saline (DPBS), $1 \times 10^{6}$ cells were suspended in serum-free medium, RPMI 1640 (GIBCO), with 1 $\mathrm{mg} \cdot \mathrm{mL}^{-1}$ bovine serum albumin (BSA) (Sigma) and $52 \mu \mathrm{L}$ of this solution was placed in the upper chambers. In chemotactic experiments different concentrations of fibronectin, laminin and collagen type IV diluted in serum-free medium containing $1 \mathrm{mg} \cdot \mathrm{mL}^{-1} \mathrm{BSA}$ were placed in the lower chambers and the filters were coated with gelatine
$100 \mu \mathrm{g} \cdot \mathrm{mL}^{-1}$ on both sides. In haptotactic experiments the underside of the filter was coated with different concentrations of ECM components using 48 well microchemotaxis chambers as previously described [23]. The lower chambers were filled with serum-free medium containing $1 \mathrm{mg}$. $\mathrm{mL}^{-1} \mathrm{BSA}$. The chambers were then incubated for $5 \mathrm{~h}$ in a well humidified incubator at $37^{\circ} \mathrm{C}$. The control used for determination of unstimulated random migration was 1 $\mathrm{mg} \cdot \mathrm{mL}^{-1} \mathrm{BSA}$ or serum-free RPMI in the lower chambers in chemotactic assays or coated on the underside of the filter in haptotactic assays. Control experiments using the adhesive molecule poly-L-lysin (PLL) instead of ECMcomponents were also performed. The motility of HUVEC cells was studied in haptotactic Boyden chamber assays with $10 \mu \mathrm{g} \cdot \mathrm{mL}^{-1}$ of laminin, fibronectin or type IV collagen coated on the underside of the membrane. In order to quantitate migration, the filters were removed from the Boyden chambers, fixed in methanol for $5 \mathrm{~min}$ and then stained with Giemsa stain for $10 \mathrm{~min}$ and rinsed in tap water. The cells were removed from the upper surface of the filter, by rubbing gently with a cotton-tipped swab. Filters were then mounted on microscope slides. The cells that migrated through the pores were counted in three randomly chosen microscope fields. All experiments were performed in triplicate and repeated three times or more. For each triplicate, the number of cells in nine microscope fields was determined and the mean \pm SD was calculated.

\section{In vitro cell migration inhibition assays}

As in the previous-assay the motility of lung cancer cells was studied using 48 well microchemotaxis chambers fitted with $12 \mu \mathrm{m}$ filters. The matrix concentration used was $10 \mu \mathrm{g} \cdot \mathrm{mL}^{-1}$ for each ECM component in haptoand chemotactic assays. The cell suspensions were preincubated with the appropriate anti-integrin antibodies (see below) at a concentration of $5 \mu \mathrm{g} \cdot \mathrm{mL}^{-1}$ for $30 \mathrm{~min}$ prior to the assay. Antibodies were present during the whole experiment. A cell suspension which had not been preincubated with integrin antibodies was used as a control. Data are presented as percentage of the control motility for the individual cell lines in all experiments.

In some experiments the interaction between fibronectin, type IV collagen and U-1810 was investigated using synthetic peptides GRGDS or GRGES. The peptides were generously provided by E.C. Kohn (National Cancer Institute, Bethesda, MA, USA). In these experiments the cell suspensions were pretreated for $30 \mathrm{~min}$ with synthetic peptides in different concentrations ranging $16-500 \mu \mathrm{g} \cdot \mathrm{mL}^{-1}$. The peptides were incubated with the cells during the haptotactic and chemotactic assay. After $5 \mathrm{~h}$ of incubation at $37^{\circ} \mathrm{C}$ the filters were fixed in methanol, stained with Giemsa and the number of cells which had migrated were counted by light microscopy as described above.

\section{Flow cytometric analysis}

Flow cytometry was performed using a FACScan analyser (Becton-Dickinson, Mountain View, CA, USA) after indirect immunofluorescence staining of cells from the five lung cancer cell lines using monoclonal antibodies. Antibodies were used at a concentration of $20 \mu \mathrm{g} \cdot \mathrm{mL}^{-1}$ and 
as negative controls rabbit anti-mouse immunoglobulin $(\operatorname{Ig}) \mathrm{G} \quad \mathrm{F}\left(\mathrm{ab}^{\prime}\right)_{2}$ were used. Fluorescein isothiocyanate (FITC)-conjugated rabbit anti-mouse $\operatorname{IgG~} \mathrm{F}\left(\mathrm{ab}^{\prime}\right)_{2}$ fragments were used for detection. The antibodies used were: $\beta 1$ integrin monoclonal antibodies (clone: DF7; BIOHIT OY, Helsinki, Finland); $\beta 2$ and $\beta 3$ integrin monoclonal antibodies (clone: 25.3 and clone S2.21 respectively; Immunotech S.A., Marseille, France); $\beta 4$ integrin monoclonal antibodies (clone: 3EI; GIBCO BRL); $\alpha 1$ integrin monoclonal antibodies (clone: TS 2/7) were generously provided by M.E. Hemler (Dana-Farber Cancer Institute, Boston, MA, USA); $\alpha 2, \alpha 3$ integrin monoclonal antibodies (clone: PTE6 and clone: P1B5 respectively, GIBCO BRL, USA); $\alpha 4, \alpha 5, \alpha 6$ and $\alpha v$ integrin monoclonal antibodies (clone: HP2/1, clone: SAM1, clone: GoH3 and clone: AMF7, respectively; Immunotech); anti-human CD44 monoclonal antibody (clone: $2 \mathrm{C} 5$; R\&D systems, Abdingdon, UK), anti-Ig and FITC-conjugated anti-IgG F(ab') fragments (Becton Dickinson).

\section{Results}

\section{Migration to ECM components}

Figure 1a-e shows representative concentration-response curves of stimulated motility over step-density gradients of substratum bound fibronectin, laminin and type IV collagen in the absence of soluble attractant. Increasing gradients of these ECM proteins resulted in an initial increase in the number of cells migrating through the filter followed by a peak or a plateau after which the migratory response declined. All cell lines showed haptotactic migration to fibronectin, laminin and type IV collagen, except for U-1810 which did not migrate to laminin.

Figure $1 \mathrm{f}-\mathrm{j}$ shows representative concentration-response curves of stimulated motility to gradients of soluble fibronectin, laminin and type IV collagen. The chemotactic migration resulted in bimodal concentration curves with a similar amplitude and peak to the haptotactic migration curves. However, U-1752 cells did not respond chemotactically to any of the three ECM components used (fig. 1g). Fibronectin and type IV collagen promoted chemotactic migration of the U-1810 cells, while laminin yielded neither chemotactic nor haptotactic migratory responses.

A concentration of $1 \mathrm{mg} \cdot \mathrm{mL}^{-1} \mathrm{BSA}$, serum-free RPMI 1640 or the adhesive molecule PLL induced negligible or no hapto- and chemotactic migration of the lung cancer cells (data not shown). These results show that the capacity of the same ECM-components to induce hapto- and chemotactic responses differed markedly between the separate cell lines and there was no distinct pattern to separate non-small cell lung cancer (NSCLC) from SCLC. The results further show that migration of lung cancer cells in the Boyden assay require adhesion molecules, soluble or substratum bound.

Under identical experimental conditions HUVEC cells migrated to laminin, fibronectin and type IV collagen (data not shown).

\section{Integrin expression by tumour cell lines}

Antibodies specific for the $\alpha$ chain of seven different integrin subunits and for the $\beta 1$ and $\beta 3$ chains were used to
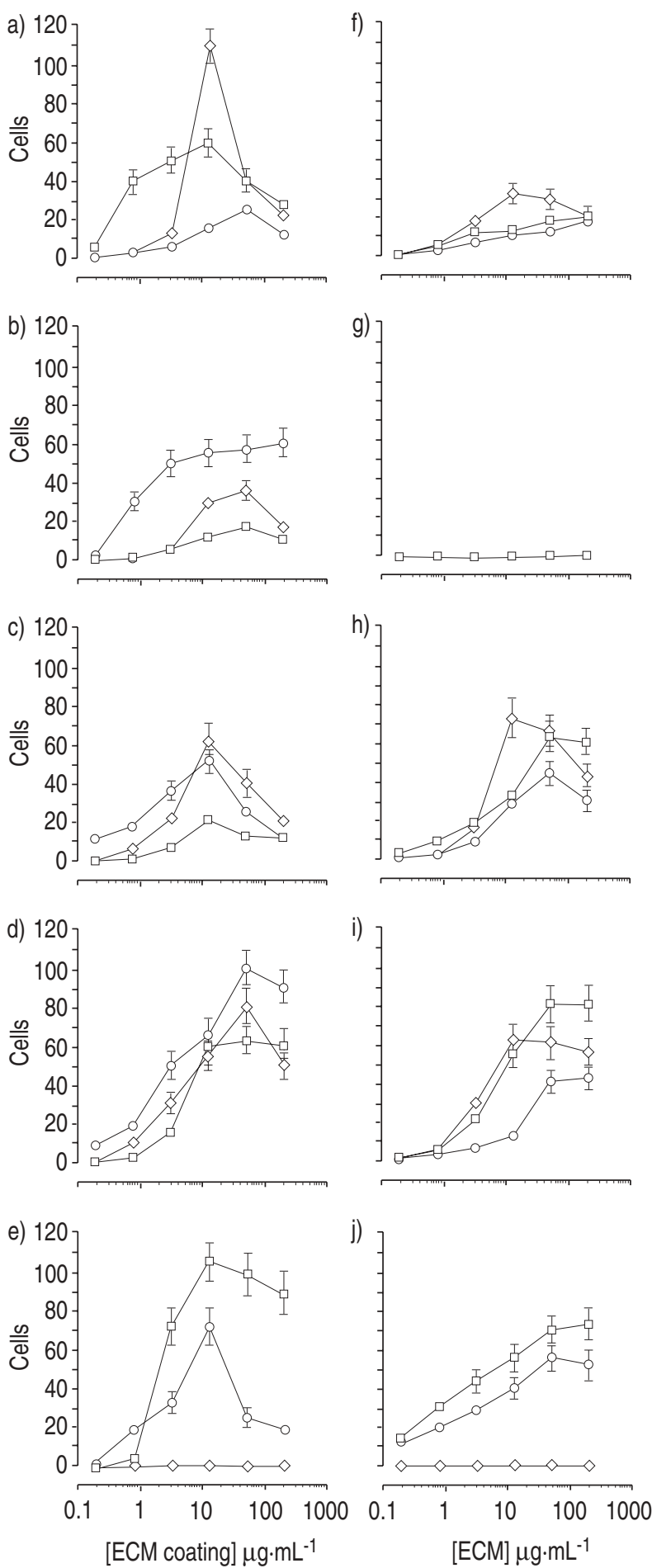

Fig. 1. - Haptotaxis of five lung cancer cell line: a) WART; b) U-1752; c) U-1906; d) $054 \mathrm{~A}$; and e) U-1810 and chemotaxis of five lung cancer cell lines: f) WART; g) U-1752; h) U-1906; i) 054 A; and j) U-1810, to fibronectin laminin and type IV collagen. In haptotactic experiments the filters were precoated with a step gradient of increasing concentrations of fibronectin $(-\square)$, laminin $(\smile \multimap)$, and type IV collagen $(-\circ)$ ). In chemotactic experiments increasing concentrations of fibronectin, laminin and type IV collagen were diluted into serum-free medium and add to the lower wells. As control protein $1 \mathrm{mg} \cdot \mathrm{mL}^{-1}$ bovine serum albumin was used. All experiments were performed in triplicates. Data presented here show the mean value of a triplicate from a single representative experiment. [ECM coating]: extracellular matrix (ECM) coating concentration. Cells: number of migrated cells/high power field $\left(4 \times 10^{2}\right)$. 

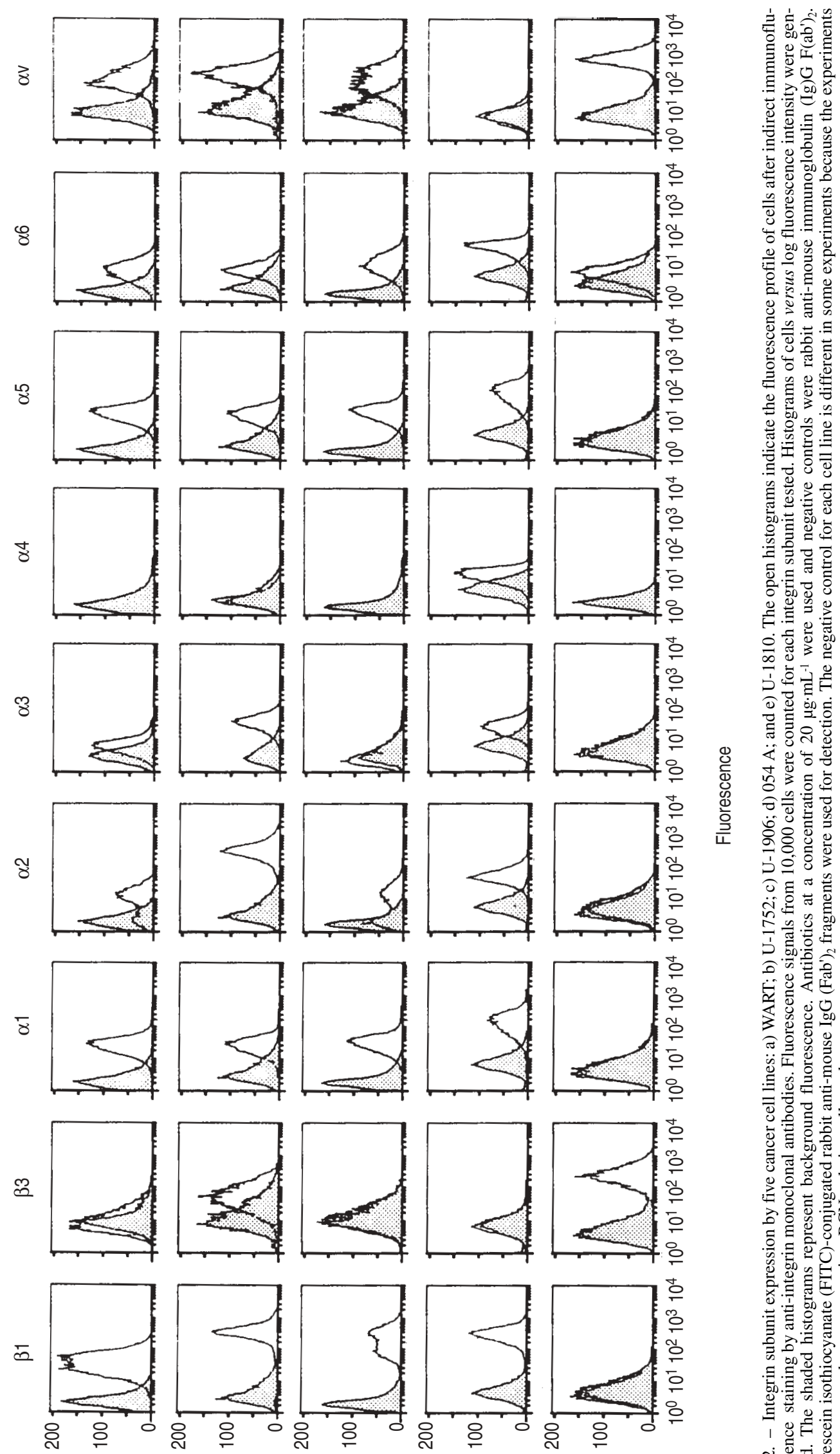

$\widehat{\sigma}$ NOY $\widehat{a}$ NOY $\sigma$ NOY $\widehat{\sigma}$ NOY $\widehat{\sigma}$ NOY

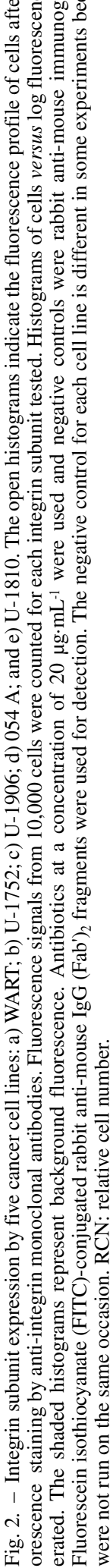


characterize the five lung cancer cell lines with respect to their cell surface integrin profile. Flow cytometric analysis was performed using monoclonal antibodies specific for integrin subunits (fig. 2). The $\beta 1$ integrin subunit was expressed on four out of five cell lines: on WART; U1752; U-1906 and 054 A. U-1810 did not express the $\beta 1$ integrin subunit. In addition, the lack of $\beta 1$ integrin expression in U-1810 was confirmed using two different antibodies P4C10 (Life Technologies) and Lia 1/2 (Immunotech) (data not shown). The $\beta 3$ integrin subunit was only expressed on U-1810 and U-1752. The expression of the fibronectin receptors $\alpha 3 \beta 1, \alpha 4 \beta 1, \alpha 5 \beta 1$ and the laminin receptors, $\alpha 3 \beta 1$ and $\alpha 6 \beta 1$ differed between the different cell lines and no distinct pattern was seen to separate NSCLC from SCLC. All cell lines except U-1810 expressed the collagen and laminin receptors $\alpha 1 \beta 1$ and $\alpha 2 \beta 1$. Thus, U-1810 expressed $\beta 3$ but not $\beta 1$ integrins. Moreover, U-1810 did not express other $\beta$ integrins such as $\beta 2$ and $\beta 4$, however, U-1810 did express CD44 (not shown). All cell lines except 054 A expressed the $\alpha \mathrm{V}$ integrin subunit.

\section{Effect of monoclonal anti-integrin antibodies on migra- tion to ECM components}

To determine whether the pattern of $\beta 1$-integrin expression correlated with the ability of the different cells to migrate to fibronectin, laminin and type IV collagen the cells in suspension were pre-incubated with the appropriate anti-integrin antibodies for $30 \mathrm{~min}$ prior to the motility assay. Control cells were incubated without antibodies. Fibronectin is a known ligand for $\alpha 3 \beta 1, \alpha 4 \beta 1$ and $\alpha 5 \beta 1$ [8]. The effect of anti- $\alpha 4$ antibodies on cell migration was, however, only tested in relation to $054 \mathrm{~A}$ since this was the only cell line expressing the $\alpha 4$ integrin subunit. $\alpha 1 \beta 1, \alpha 2 \beta 1$ and $\alpha 3 \beta 1$ are both laminin and collagen receptors and $\alpha 6 \beta 1$ is a receptor for laminin [8]. We selected anti- $\alpha 3$ and anti- $\alpha 6$ antibodies to match laminin and anti- $\alpha 1$, anti- $\alpha 2$ and anti- $\alpha 3$ antibodies to match type IV collagen in the migration assays. Anti- $\alpha \mathrm{V}$ antibodies were tested in relation to all cell lines (except 054 A which did not express the $\alpha v$ integrin subunit) exposed to fibro-nectin, laminin and type IV collagen. Anti- $\beta 3$ antibodies were only tested in relation to U-1810 and U-1752.

As shown in figure 3 the $\beta 1$-integrin subunit is important for both hapto- and chemotactic migration towards all three ECM components tested for WART, U-1752, U1906 and 054 A. Anti- $\beta 1$ integrin antibodies did not significantly inhibit hapto- or chemotactic migration of U1810 . The $\beta 3$-integrin subunit has little or no importance for hapto- and chemotactic migration for U-1752 and U1810 .

The $\alpha 5$ integrin is the most important $\alpha$-subunit for both hapto- and chemotactic migration to fibronectin in all cell lines except U-1810. Likewise, the $\alpha 6$-integrin is the most important $\alpha$-subunit for both hapto- and chemotactic migration to laminin in all cell lines except in haptotactic assays for $054 \mathrm{~A}$ where the $\alpha 3$ integrin is the most important $\alpha$-subunit (no assay was run for U-1810 since this cell line does not migrate to laminin). The $\alpha 2$ integrin is the most important $\alpha$-subunit for both hapto- and chemotactic migration to type IV collagen in all cell lines except in hapto- and chemotactic assays for U-1810 and in haptotactic assays for $054 \mathrm{~A}$. The $\alpha \mathrm{v}$ integrin is important for
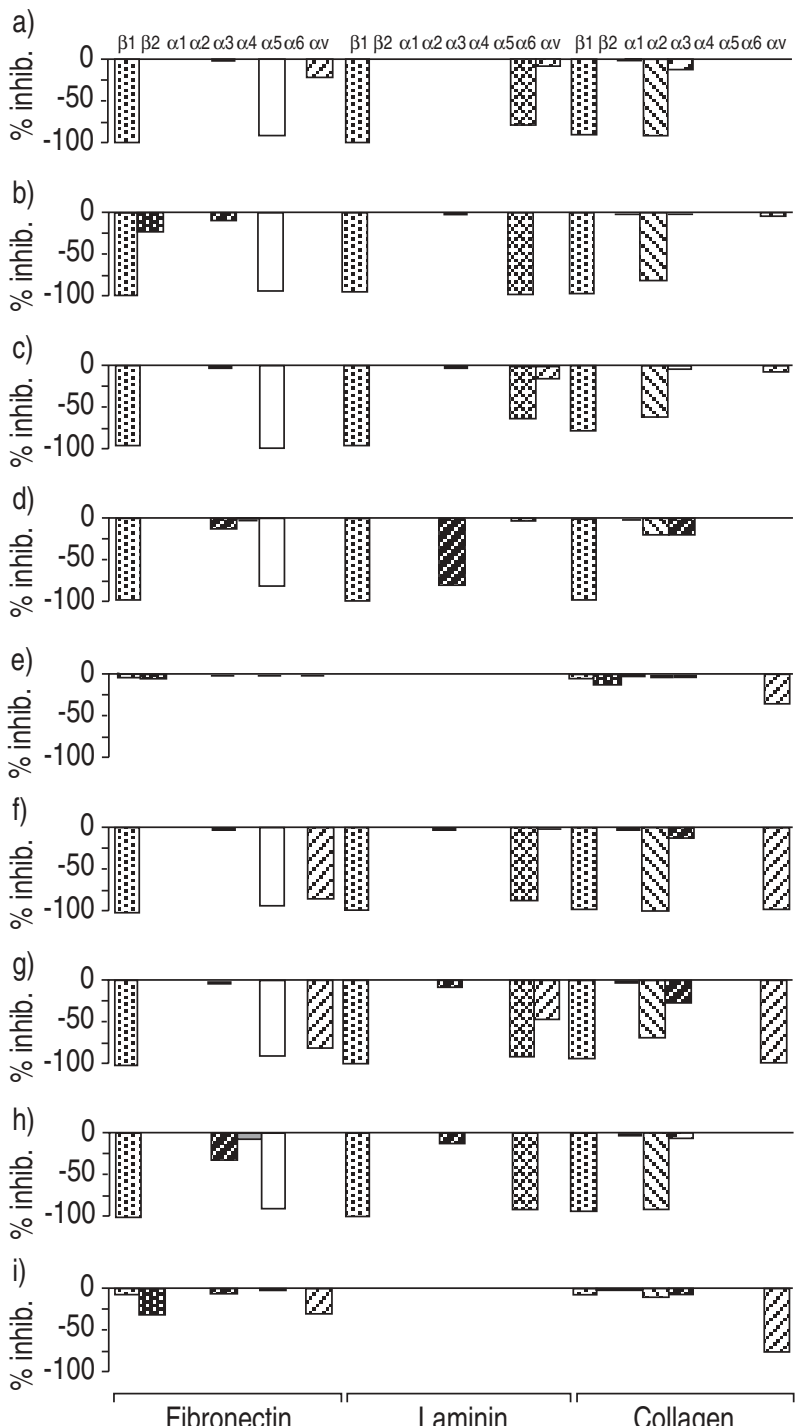

Fibronectin Laminin $\longdiv { \text { Collagen } }$

Fig. 3. - Effect of monoclonal anti-integrin antibodies on haptotactic migration to fibronectin, laminin and type IV collagen in five lung cancer cell lines: a) WART; b) U-1752; c) U-1906; d) 054 A; and e) U-1810 and the effect of monoclonal anti-integrin antibodies of chemotactic migration to fibronectin, laminin and type IV collagen in four lung cancer cell lines: f) WART; g) U-1906; h) 054 A; and i) U-1810. The cell suspensions were pre-incubated with $5 \mu \mathrm{g} \cdot \mathrm{mL}^{-1}$ of the appropriate antiintegrin antibodies for $30 \mathrm{~min}$ at room temperature prior to the assay, and antibodies remained incubated with the cancer cells throughout the assay. The matrix concentration used was $10 \mu \mathrm{g} \cdot \mathrm{mL}^{-1}$ for each component. Control cells were incubated without antibodies. Data are presented as percentage of the control motility for the individual cell line \pm S EM. Complete inhibition of migration is indicated as $-100 \%$. The \pm E M variations was $<5 \%$ of the average values for large cell lung cancer (LCLC) and $<13 \%$ for small cell lung cancer (SCLC), adenocarcinoma and squamous cell lung cancer. Ab: antibody.

chemotactic migration to fibronectin in WART and U1906 and to type IV collagen in WART, U-1906 and U1810. The $\alpha v$-integrin subunit was of minor importance in haptotactic assays to type IV collagen in U-1810.

\section{Effect of peptide GRGDS on migration to ECM components}

The RGD sequence is the cell recognition site of a number of ECM and platelet adhesion proteins. For example: vitronectin, type I collagen, fibronectin [24] and their 


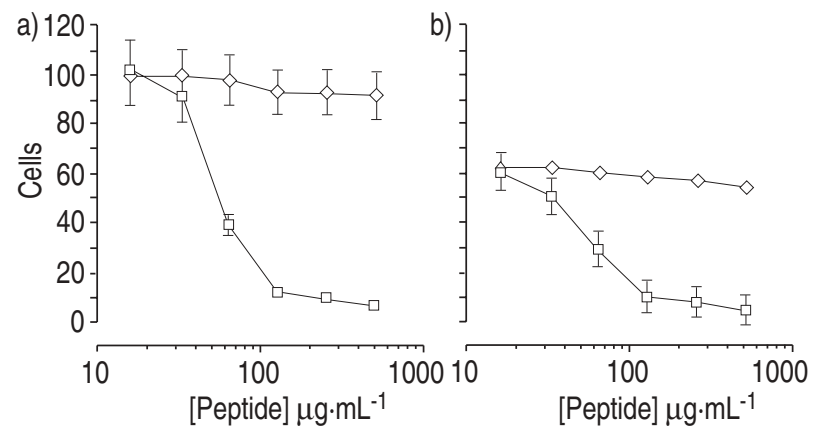

Fig. 4. - Effect of: a) haptotactic and b) chemotactic migration of U1810 to fibronectin. The cell suspensions were pre-incubated with increasing concentrations $\left(16-500 \mu \mathrm{g} \cdot \mathrm{mL}^{-1}\right)$ of the peptide GRGDS. GRGES was used as a negative control. The fibronectin concentration used in chemotactic assays was $10 \mu \mathrm{g} \cdot \mathrm{mL}^{-1}$. All experiments were performed in triplicate. Data presented here show the mean \pm E M values of a triplicate from a single representative experiment. $-\square-$ : GRGDS; $\prec-$ GRGES; Cells: number of migrated cells/high power field $\left(4 \times 10^{2}\right)$.

interaction with cells can be inhibited with RGD-containing peptides. To determine if the RGD site was necessary to generate a motile response to fibronectin and type IV collagen, U-1810 cells were pretreated with increasing concentrations $\left(16-500 \mu \mathrm{g} \cdot \mathrm{mL}^{-1}\right)$ of the peptide GRGDS. GRGES was used as a negative control. As shown in figure 4 GRGDS caused almost $100 \%$ inhibition of haptoand chemotactic migration to fibronectin. Negligible (9\%) inhibition was observed when cells were pretreated with negative control peptide GRGES. Similar results were seen in hapto- and chemotactic migration to type IV collagen when U-1810 cells were pretreated with increasing concentrations $\left(16-500 \mu \mathrm{g} \cdot \mathrm{mL}^{-1}\right)$ of the peptide GRGDS (data not shown). Thus, the RGD sequence was probably necessary to generate hapto- and chemotactic responses, not only to fibronectin, but also to type IV collagen in U-1810 cells.

\section{Discussion}

The main finding in this study is the involvement of $\beta 1$ integrins in lung cancer cell migration in vitro towards fibronectin, laminin and type IV collagen. The migration inhibition assays showed that both hapto- and chemotactic migration towards fibronectin, laminin and type IV collagen was $\beta 1$ integrin-dependent in all cell lines, except U1810. However, the $\beta 1$ integrin subunit negative cell line U-1810, which did not express fibronectin or collagen receptors, did migrate both hapto- and chemotactically to fibronectin and type IV collagen probably by using CD44.

U-1906, 054 A, WART and U-1752 all expressed $\beta 1$ integrins whereas U-1810 did not. However, U-1810 and U-1752 expressed $\beta 3$ integrins. Several studies have focused on the integrin expression of lung cancer cells but have not clearly shown distinct patterns of integrin expression among various histological types of lung cancer $[15$, 25-27]. Most lung cancer cell lines as well as normal bronchial epithelial cells, however, express the $\beta 1$ integrin subunit $[25,27]$. The present study confirms that lung cancer cells in culture express a variety of $\beta 1$ integrins. The U-1810 cell line, however, clearly differed from the rest of the lines by lacking expression of $\beta 1$ integrins. Lung cancer cell lines with a weak or total absence of $\beta 1$ integrin expression have been described previously [25].
The pres-ent study revealed no distinct pattern in SCLC and NSCLC in terms of expression of $\alpha$ or $\beta 1$ integrin subunits. FeLDMAN et al. [28] reported that SCLC cells most consistently express the $\alpha 3 \beta 1$ integrin. Our analyses revealed that only one of the two SCLC cell lines, 054 A, expressed the $\alpha 3 \beta 1$ integrin. The $\alpha \mathrm{v}$ integrin subunit is represented on four out of five cell lines, the $\beta 3$ integrin subunit only on two, indicating that the former subunit associates with other $\beta$ integrin subunits in the rest of the cell lines. The ability of the $\alpha \mathrm{v}$ subunit to combine with alternative $\beta$ subunits is well documented [7].

The hapto- and chemotactic responses differed markedly between the separate cell lines and there was no distinct pattern to separate NSCLC from SCLC. No or very little migration was seen in control experiments with BSA or serum-free medium alone indicating that the migration of the lung cancer cells is crucially dependent on adhesive interactions between the cells and ligands such as the ECM. The migratory properties of the five tumour cell lines was compared to those of HUVECs, under identical experimental conditions. As expected the HUVECs migrated to all three ECM components used (data not shown).

The migratory characteristics of the lung tumour lines to the ECM-components were heterogeneous. The concentration-response curves of haptotactic motility to laminin, fibronectin and type IV collagen were bimodal, except in U-1752 to type IV collagen. The chemotactic migration to laminin also resulted in bimodal concentration curves. This type of curve has been observed previously in the motility response of a Schwann cell tumour line to laminin [29], and of a human melanoma cell line to laminin and fibronectin [10]. The bimodal migratory response may represent competition of sites, functional downregulation of integrins or strong adhesion at high concentrations of attractants.

U-1752 cells did not respond chemotactically to any of the three ECM components used. Yet, the inability of U1752 cells to respond chemotactically to fibronectin, laminin and type IV collagen in the present study might be explained by induction of different signal transduction ways. As previously shown by AzNavoorian et al. [10] transduction of signals initiating motility by ECM proteins differs depending on the type of matrix molecule and whether the molecule is in solution or bound to a substratum. After pretreatment with pertussis toxin, chemotactic responses to type IV collagen was profoundly inhibited. In contrast to the inhibition of chemotaxis, the haptotactic response to type IV collagen was unaffected after pretreatment with pertussis toxin. The results of TARABOLETTI et al. [30] suggest that separate domains of the ECM protein (thrombospondin) are responsible for mediating tumour cell chemotaxis versus haptotaxis.

Our results indicate that, although some cell lines expressed high amounts of a certain integrin subunit, the selective dependence of this cell line on this integrin subunit for migration towards a specific ECM component does not simply reflect the surface expression. For example the $\alpha 3$ integrin subunit did not seem to be important for migration of U-1752 (expressing high amounts of the $\alpha 3$-integrin subunit) to fibronectin. The $\alpha 4$ integrin subunit was not important for migration of 054 A (the only cell line expressing the $\alpha 4$-integrin subunit) to fibronectin.

U-1810 cells showed neither hapto- nor chemotactic migratory responses to laminin. This inability is consistent 
with their lack of the $\alpha 6 \beta 1$ integrin. However, hapto- and chemotactic migratory responses were induced by both fibronectin and type IV collagen although none of the fibronectin- and type IV collagen-binding integrins tested were involved in the migration. A possible explanation for $\beta 1$ integrin negative cells being able to migrate to type IV collagen could be that they utilize the adhesion molecule CD44. As shown by KNuTson et al. [31] CD44 and $\alpha 2 \beta 1$ mediates human melanom cell migration on type IV collagen and invasion of basement membranes. Furthermore CD44 is also shown to play a role in adhesive interactions between glioma cells and both fibronectin and type IV collagen [32]. It may be fruitful to further investigate the migration of U-1810 to fibronectin and type IV collagen and the possible significance of CD44. Furthermore, our results indicate that migration of U-1810 cells to both fibronectin and type IV collagen requires cellular interaction with the RGD site. Collagen-binding integrins isolated so far have been found to be refractory to inhibition with RGD-containing peptides [33]. The $\alpha$ v integrin subunit is probably responsible for a part of the chemotactic migration of U-1810 cells to fibronectin and type IV collagen and for haptotactic migration to collagen type IV as demonstrated by the inhibitory cell migration assays. This RGD-dependence suggests an integrin-related mechanism for the U-1810 interaction with fibronectin resulting in haptotactic migration.

The downregulation of cell adhesion molecules (CAMs) is probably necessary for the release of the neoplastic cells from the primary tumour [6]. Several authors have shown that the loss of epithelial (E)-cadherin expression is correlated to dedifferentiation, invasiveness, and poor prognosis in gastric cancer, breast cancer, hepatocellular carcinoma, and head and neck cancer ([34] and references therein). In lung cancer the biological significance of the E-cadherin expression is so far unclear. However, Böнm et al. [35] found a correlation between dedifferentiation and down regulation of E-cadherin expression in poorly differentiated squamous cell lung carcinomas. No such association was found in adenocarcinomas of the lung.

Most lung cancer cell lines as well as normal bronchial epithelial cells express the $\beta 1$ integrin subunit [25, 27]. The present study confirms that lung cancer cells in culture express a variety of $\beta 1$ integrins. The U-1810 cell line, however, clearly differed from the rest of the lines by lacking expression of $\beta 1$ integrins. Previously HIRASAWA et al. [25] have described lung cancer cell lines with weak or total absence of $\beta 1$ integrins. The possible association between the loss of $\beta 1$ integrin expression and the biological behaviour of the tumour cells is so far unknown.

The role of integrins for the migration of lung cancer cells has not previously been extensively investigated. Several factors make it difficult to draw definitive conclusions regarding the role of individual $\beta$ integrins in tumour pathogenesis. These include the presence of different integrins on each cell line which have overlapping binding capabilities and the fact that the cells usually express more than one integrin.

Our results illustrate the complexity of tumour cell migration in response to extracellular matrix proteins in vitro. The most important finding in this study is the involvement of $\beta 1$ integrins in lung cancer cell migration in vitro towards fibronectin, laminin and type IV collagen.

\section{References}

1. Liotta LA. Tumor invasion and metastases-role of the extracellular matrix. Cancer Res 1986; 46: 1-7.

2. McCarthy JB, Basara ML, Palm SL, Sas DF, Furcht LT. The role of cell adhesion proteins - laminin and fibronectin - in the movement of malignant and metastatic cells. Cancer Metast Rev 1985; 4: 125-152.

3. Liotta LA, Rao CN. Barsky SH. Tumor invasion and the extracellular matrix. Lab Invest 1983; 49: 636-649.

4. Rickard KA, Taylor J. Rennard SI, Spurzem JR. Migration of bovine bronchial epithelial cells to extracellular matrix components. Am J Respir Cell Mol Biol 1993; 8: 63-68.

5. Terranova VP, Maslow D, Markus G. Directed migration of murine and human tumor cells to collagenases and other proteases. Cancer Res 1989; 49: 4835-4841.

6. Albelda SM. Role of integrins and other cell adhesion molecules in tumor progression and metastasis. Lab Invest 1993; 68: 4-17.

7. Hynes RO. Integrins: Versality, modulation, and signaling in cell adhesion. Cell 1992; 69: 11-25.

8. Ruoslahti E, Giancotti F. Integrins and tumor cell dissemination. Cancer Cells 1989; 1: 119-126.

9. Yamada KM, Kennedy DW, Yamada SS, Gralnick H, Chen W-T, Akiyama SK. Monoclonal antibody and synthetic peptide inhibitors of human tumor cell migration. Cancer Res 1990; 50: 4485-4496.

10. Aznavoorian S, Stracke ML, Krutzsch H, Schiffmann E, Liotta LA. Signal transduction for chemotaxis and haptotaxis by matrix molecules in tumor cells. J Cell Biol 1990; 110: 1427-1438.

11. Juliano RL, Haskill S. Signal transduction from the extracellular matrix. J Cell Biol 1993; 120: 577-585.

12. Giancotti FG, Ruoslahti E. Elevated levels of the $\alpha 5 \beta 1$ fibronectin receptor suppress the transformed phenotype of chinese hamster ovary cells. Cell 1990: 60: 849-859.

13. Schreiner C, Fisher M, Hussein S, Juliano RL. Increased tumorigenicity of fibronectin receptor deficient chinese hamster ovary cell variants. Cancer Res 1991; 51: 17381740.

14. Albelda SM. Mette SA, Elder DE, Stewart R, Damjanovich L, Herlyn M. Integrin distribution in malignant melanoma: association of the $\beta 3$ subunit with tumor progression. Cancer Res 1990; 50: 6757-6764.

15. Damjanovich L, Albelda SM, Mette SA, Buck CA. Distribution of integrin cell adhesion receptors in normal and malignant lung tissue. Am J Respir Cell Mol Biol 1992; 6: 197-206.

16. Plantefaber LC, Hynes RO. Changes in integrin receptors on oncogenically transformed cells. Cell 1989; 56: 281-299.

17. Chen FA, Alosco T, Croy BA, Narumi K, Percy DH, Bankert RB. Clones of tumor cells derived from single primary human lung tumor reveal different patterns of beta 1 integrin expression. Cell Adhes Commun 1994; 2: 345-357.

18. Klominek J, Sundqvist K-G, Robért K-H. Nucleokinesis: Distinct pattern of cell translocation in response to an autocrine motility factor-like substance or fibronectin. Proc Natl Acad Sci USA 1991; 88: 3902-3906.

19. Bergh J, Nilsson K, Zech L, Giovanella B. Establishment and characterization of a continuous lung squamous cell carcinoma cell line (U-1752). Anticancer Res 1981; 1: 317-322.

20. Bergh J, Nilsson K, Ekman R, Giovanella B. Establishment and characterization of cell lines from human small cell and large cell carcinomas of the lung. Acta pathologica microbiol immunol scandinavia Sect A 1985; 93: 133-147. 
21. Engelholm SA, Spang-Thomsen M, Vindeløv LL, et al. Comparison of characteristics of human small cell carcinoma of the lung in patients, in vitro and transplanted into nude mice. Acta pathologica microbiol immunol scandinavia Sect A 1986; 94: 325-336.

22. Jaffe EA. Endothelial cells and the biology of factor VIII. N Engl J Med 1977; 296: 377-383.

23. Klominek J. Robért K-H, Sundqvist K-G. Chemotaxis and haptotaxis of human malignant mesothelioma cells: effects of fibronectin, laminin, type IV collagen, and an autocrine motility factor-like substance. Cancer Res 1993; 53: 4376-4382.

24. Ruoslahti E. Integrins. J Clin Invest 1991; 87: 1-5.

25. Hirasawa M. Shijubo N, Uede T, Abe S. Integrin expression and ability to adhere to extracellular proteins and endothelial cells in human lung cancer lines. Br J Cancer 1994; 70: 466-473.

26. Mette SA. Pilewski J, Buck CA, Albelda SM. Distribution of integrin cell adhesion receptors on normal bronchial epithelial cells and lung cancer cells in vitro and in vivo. Am J Respir Cell Mol Biol 1993; 8: 562-572.

27. Suzuki S. Takahashi T, Nakamura S, et al. Alterations of integrin expression in human lung cancer. Jpn J Cancer Res 1993; 84: 168-174.

28. Feldman LE, Shin KC, Natale RB, Todd III RF. $\beta 1$ integrin expression on human small cell lung cancer cells. Cancer Res 1991; 51: 1065-1070.
29. McCarthy JB, Palm SL, Furcht LT. Migration by haptotaxis of a Schwann cell tumor line to the basement membrane glycoprotein laminin. J Cell Biol 1983; 97: 772-777.

30. Taraboletti G, Roberts DD, Liotta LA. Thrombospondininduced tumor cell migration: haptotaxis and chemotaxis are mediated by different molecular domains. J Cell Biol 1987; 105: 2409-2415.

31. Knutson JR, Iida J, Fields GB, McCarthy JB. CD44/ chondroitin sulfate proteoglycan and alpha 2 beta I integrin mediate human melanoma cell migration on type IV collagen and invasion of basement membranes. Mol Biol Cell 1996; 7: 383-396.

32. Radotra B, McCormick D, Crockard A. CD44 plays a role in adhesive interactions between glioma cells and extracellular matrix components. Neuropathol Appl Neurobiol 1994; 20: 399-405.

33. Gullberg D, Terracio L, K. BT, Rubin K. Identification of integrin-like matrix receptors with affinity for interstitial collagens. J Biol Chem 1989: 264: 12686-12694.

34. Sorscher SM. Russack V, Graziano S, Cagle M, Feramisco JR, Green MR. Immunohistochemical evaluation of E-cadherin and epidermal growth factor. Mod Pathol 1995; 8: 450-455.

35. Böhm M. Totzeck B, Wieland I. Differences of E-cadherin expression levels and patterns in human. Annals Hematol 1994; 68: 81-83. 